\title{
Prevalence of Impacted Canine Among Adult Orthodontic Patients: A Retrospective Study
}

\section{Ismail Ibrahim Alhabeebi ${ }^{1 *}$, Manal Yehia Foda ${ }^{2}$, Eman Mohie El-Din El-Sayed ${ }^{3}$ and Mustafa Mohamed El Dawlatly ${ }^{4}$}

${ }^{1}$ MSc Student of Orthodontics, Division of Orthodontics, Faculty of Dentistry, Cairo

University, Cairo, Egypt

${ }^{2}$ Professor of Orthodontics, Faculty of Dentistry, Cairo University, Cairo, Egypt

${ }^{3}$ Associate Professor of Orthodontics Department, Faculty of Dentistry, Cairo

University, Cairo, Egypt

${ }^{4}$ Lecturer of Orthodontics, Faculty of Dentistry, Cairo University, Cairo, Egypt

*Corresponding Author: Ismail Alhabeebi, MSc Student of Orthodontics, Division

of Orthodontics, Faculty of Dentistry, Cairo University, Cairo, Egypt.
Received: November 15, 2021

Published: December 13, 2021

(C) All rights are reserved by Ismail Ibrahim

Alhabeebi., et al.

\begin{abstract}
Aim: The current research was to estimate the prevalence of impacted canines among the Egyptian population; the following parameters were included as sex, age, number, position, laterality and associated pathology with impacted Canine.

What is the prevalence of impacted Canine among orthodontic clinics in the Egyptian population? Additionally, to correlates between peg-shaped lateral teeth and missing the second premolar in different levels of each quadrant.

Methodology: Panoramic radiographs were recruited from the orthodontic department clinics in multiple universities in Egypt (Cairo, Ain shams, Alexandria, and Al-Azhar University). Complete orthodontic records, including radiographs, of 3560 patients who sought malocclusion treatment between April 2020 and September 2020 were retrieved for this study; after filtration of these panoramic radiographs, 184 radiographs were included in the study that fulfilled the lasted criteria.

Results: After filtration of these panoramic radiographs, 184 panoramic were included in this study; at least one impacted canine teeth were noted in $5.28 \%$ of patients. Most common impacted canine teeth in the maxilla (84.4\%) and the mandibular (15.5\%). In gender, males (35.1\%), while females (64.9\%). The comparison revealed an insignificant difference between percentages with the same superscript letters (right and left side maxillary canine - right and left side mandibular Canine).

A weak correlation was found between impacted canine and missed wisdom, missed the second premolar, and peg-shaped lateral incisor.

Conclusions: The Prevalence of impacted canine teeth among orthodontic clinics in the Egyptian population in this study is 5.28\%, and there is a significant, weak correlation with peg-shaped lateral incisor teeth, missing second premolar and missing wisdom teeth.
\end{abstract}

Keywords: Radiographs; Occlusion; Eruption

\section{Introduction}

The permanent canines are the foundation and pillar of an aesthetic smile and functional occlusion. It is the cornerstone of the dental arch forming the canine eminence to support the alar base and upper lip. It plays a vital role in facial appearance, dental es- thetics, arch development, and functional occlusion). Functionally, it supports the dentition contributing to its disarticulation in lateral movements in specific individuals. Its root length, unusually its volume, makes it one of the most outstanding abutments for prosthetic replacement of other maxillary teeth. 
Tooth eruption is defined as the axial movement of a tooth from its developmental site within the alveolar bone to its functional position in the dental arch [22]. Eruption begins only after the mineralization of the crown is completed. It requires resorption of the alveolar bone and, in the case of the permanent dentition, resorption of the primary deciduous tooth [5]. Several mechanisms control the eruption process, taking into account the predetermined location, the onset at a specific age, and synchronization with its contralateral tooth. For descriptive purposes, the eruption process can be divided into intra-osseous and supra-osseous [35]. Intraosseous events involve bone resorption and translocation of the developing tooth within the bone. Supra-osseous events include the tooth's movement once a section of the crown has surpassed the alveolar crest.

Canine has the most extended period of development and the most tortuous route to complete occlusion. For this reason, it is considered the third most common tooth to be impacted, next to mandibular and maxillary third molars. The prevalence of impacted maxillary canines ranges from a minimum of $0.92 \%$ to a maximum of $4.3 \%$.

As the eruption process is so complex, problems may inevitably arise, leading to tooth retardation or eruption failure (impaction). If the tooth is not exposed to the oral cavity and the patient's age was above 16 years, the Canine is considered to be impacted.

Impaction is defined as a tooth that is prevented from erupting ultimately into its normal functional position by bone and tooth or fibrous tissue within the expected time due to a long, tortuous path of eruption, tooth size and arch length discrepancies, arch width deficiencies, microform, or absent lateral incisors, familial tendency, genetics, population differences, lack of resorption of the deciduous canine root, abnormal position of the tooth bud, presence of an alveolar cleft, and cystic or neoplastic formation.

The management of impacted canines requires accurate Diagnosis and precise location of the impacted Canine and the surrounding structures. Diagnosis and identification of the position can be difficult with conventional radiographic methods because of the superimposition of systems on the film, making it difficult to distinguish details. A newer technique like CT/CBCT and rapid prototyping is more promising and accurate.

Computed tomographic scanning (CT) has recently been used because it can provide more reliable information than convention- al methods. CT scanning is a method in which clear serial radiographs may be taken at graduated depth in any human body part. Due to more CT dosage, CBCT came into play with decreased radiation dose, high resolution, and excellent tissue contrast. CBCT use has generally been justified when 2-dimensional radiography has not provided the necessary information required in the management and treatment planning and when the information gained from CBCT examination would aid this.

The diagnosis and treatment of this problem usually require the expertise approach and cooperation of the general practitioner, oral surgeon, periodontist, and orthodontist. Knowing the prevalence of impacted teeth is essential for the practitioner to recognize and interceptive treatment of impacted teeth.

This study was conducted to determine the prevalence of impacted maxillary and mandibular canines in different Egyptian populations.

\section{Material and Methods}

Material

Study design: This study was designed as a cross-sectional retrospective study.

\section{Setting}

Participants: The subjects included panoramic radiographs of Egyptians between ages 16-40 years old.

\section{Studied population}

Panoramic radiographs were recruited from the orthodontic department clinics in multiple universities in Egypt (Cairo, Ain shams, Alexandria, and Al-Azhar University) for six months from April to September of 2020. The study was conducted on 184 panoramic radiographs. The College Research Committee College approved it Dentistry, Cairo University, Egypt.

\section{Eligibility criteria}

Panoramic radiographs enrolled in this research included the following criteria.

\section{Inclusion criteria}

Egyptian patients with panoramic malocclusion.

- $\quad$ Age: 16-40 Years old.

- Sex: Both sexes were included. 


\section{Exclusion criteria}

- Previous orthodontic treatment.

- Permanent canine extraction.

- Intraoral pathological lesion related to canine area.

- Radiographs of poor quality.

- Any hereditary diseases or syndromes such as Down's syndrome or cleidocranial dysostosis.

- Any disease, trauma, or fracture of the jaw might have affected the average growth of permanent dentition.

\section{Sample size calculation}

Sample size calculation was done using the R statistical package, version 3.3.1 (21-06-2016).

Copyright (C) 2016. The R Foundation for Statistical Computing (1).

Cochran's Sample Size Formula for Prevalence studies was used to detect the proper sample size. Means and standard deviations were determined according to Moreira., et al. (2015) based on the prevalence of impacted canines.

At a 95\% Confidence Interval and a 3\% margin of error, the sample size is 184 participants.

\section{Population definition}

Governmental major universities in Egypt (Cairo, Ain shams, Alexandria, and Al-Azhar University) orthodontic department clinics during April 2020 and September 2020.

\section{Methods}

Complete orthodontic records, including radiographs, of 3560 patients who sought malocclusion treatment between April 2020 and September 2020 were retrieved for this study.

A data entry form was explicitly prepared to record the status of impacted canines and subjects characteristics figures 1 and 2 .

\section{Personal information chart}

Personal data including name, age, date of birth, gender were collected from the patient files in the orthodontic department clinic.

\section{Interpretation panoramic radiograph}

A single skilled dentist scrutinized all radiographs on a transparency projector under constant lighting conditions. All radio- graphs were determined for the number of impacted teeth in the maxilla and mandible and the male and female populations.

In the present study, impacted canines were classified based on angulations and depths of the involved teeth. In terms of angulation, impacted canines were classified as mesioangular, distoangular, vertical, or horizontal.

- Age range distribution among gender.

- Determine the number of impacted canines in each quadrant and compare each of them.

- In each quadrant of impacted Canine determine the characteristics as

- Height Level of crown To Occlusal Plane.

- Transverse nearest of the crown in relation to Midline at Distant or Close.

- Canine Position

- Buccal

- Lingual or Palatal

- Canine Angulation to Midline in 3 groups:

- $(0-15)$

- $(15-30)$

- $(>30)$

- Position of The Canine Apex Related to the Adjacent Teeth

- Canine zone

- $\quad 1^{\text {st }}$ premolar zone

- $\quad 2^{\text {nd }}$ premolar zone

- Mesiodistal Position of Canine Tip to Adjacent Tooth

- Distal

- Distal to the long axis

- Mesial to the long axis

- Mesial

- Comparison between all quadrants regarding all parameters.

- Correlation between impacted Canine and peg-shaped lateral incisor teeth.

- $\quad$ Correlation between impacted Canine and missing $2^{\text {nd }}$ premolars teeth.

- $\quad$ Correlation between impacted Canine and missing wisdom teeth. 


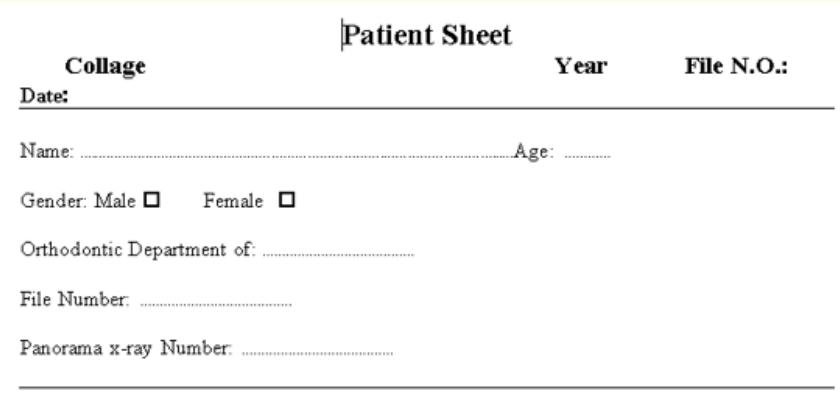

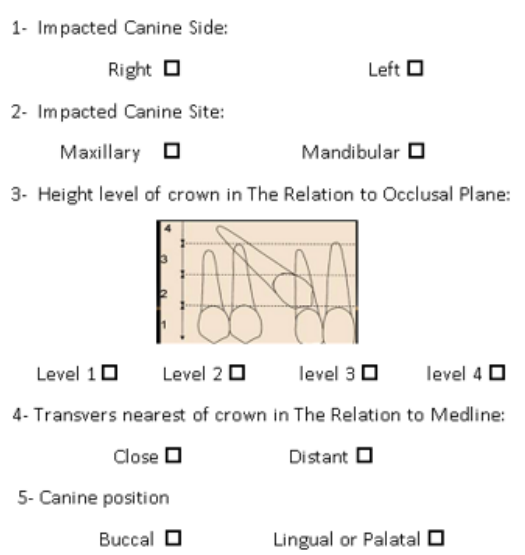

Figure 1: Patient sheet 1.

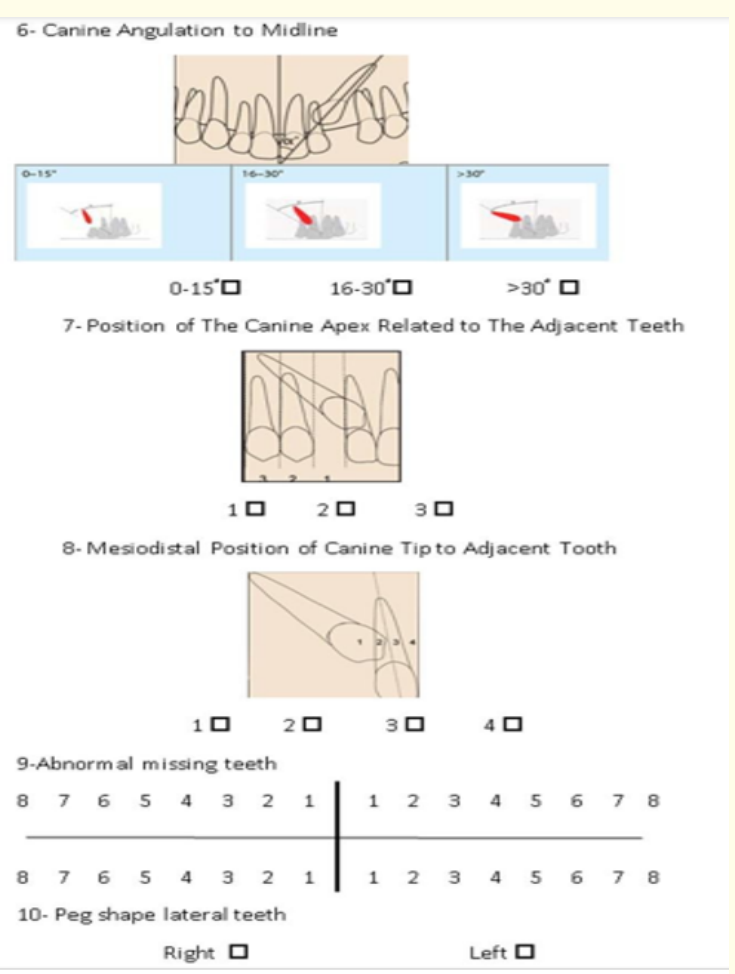

Located the unerupted canine cusp tip relative to the lateral incisor root in one of four sectors using a modified method of Ericson and Kurol"s 20. He evaluated the panoramic radiographs taken during the late mixed dentition period and classified them into four sectors, as shown in figure 3.

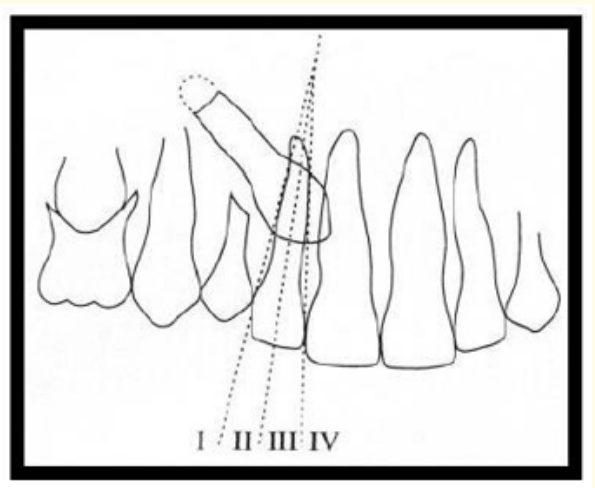

Figure 3: Lindauer's classification.

- Sector I: The area distal to a line tangent to the distal heights of a contour of the lateral incisor crown and root.

- $\quad$ Sector II: The area mesial to the sector I but distal to a line bisecting the lateral incisor's mesiodistal dimension along the long axis of the tooth.

- Sector III: The area mesial to sector II, but distal to a line tangent to the mesial heights of a contour of the lateral incisor crown and root.

- $\quad$ Sector IV: All areas mesial to sector III.

According to the depth of the impactions (Figure 1) was classified as Level 1, Level 2, and Level 3 as follows: (Yavuz MS., et al. 2007, p. 78).

- Level 1: The crown of the impacted canine tooth is at the cervical line of the adjacent teeth.

- Level 2: The crown of the impacted canine tooth is between the adjacent teeth' cervical line and root apices.

- Level 3: The crown of the impacted canines is beneath the root apices of the adjacent teeth.

When an impacted tooth was identified, the presence, absence, Inadequate space, resorption of root of lateral teeth, retention of deciduous Canine, and development/eruption of the patient's other teeth were also assessed.

Figure 2: Patient sheet 2. 
A tube shift method is commonly employed in clinical settings (horizontal and vertical tube shift) to locate an impacted canine's correct position.

\section{Statistical analysis}

Statistical analysis was performed using SPSS $20^{\circledR} 1$, Graph Pad Prism ${ }^{\circledR}$ 2, and Microsoft Excel 20163. Data were represented as the mean and standard deviation for quantitative data and frequency and percentages for qualitative. As presented in (1) tables and (4) graphs.

Comparison between two groups was performed by independent t-test for quantitative data, and chi-square test for qualitative data.

Spearman's correlation coefficient was calculated for qualitative data to evaluate the level of correlation needed in this study. The values range between -1.0 and 1.0. A correlation of -1.0 shows a perfect negative correlation, while a correlation of 1.0 indicates a perfect positive correlation.

Results

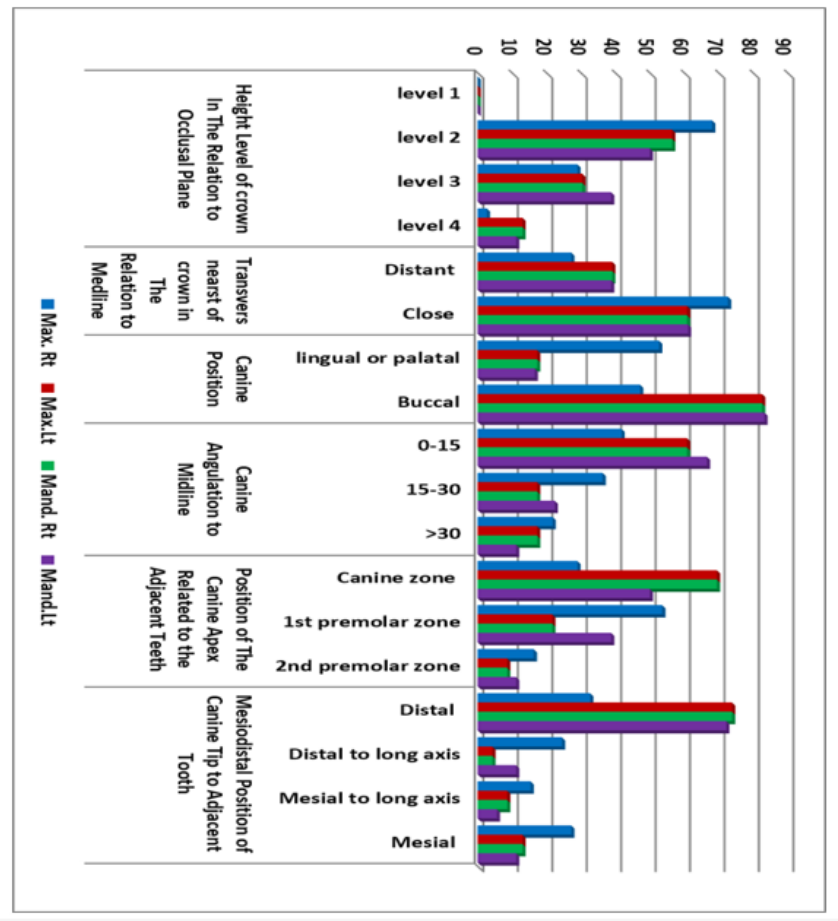

Figure 4: Pie chart showing Comparison between all quadrants regarding all parameters.

\begin{tabular}{|c|c|c|c|c|c|c|}
\hline \multicolumn{2}{|l|}{ Canine Impaction } & $\begin{array}{c}\text { Max. Rt. \% } \\
(n=110)\end{array}$ & $\begin{array}{l}\text { Max. Lt. \% } \\
(n=113)\end{array}$ & $\begin{array}{c}\text { Mand. Rt. \% } \\
(n=23)\end{array}$ & $\begin{array}{c}\text { Mand. Lt. \% } \\
(n=18)\end{array}$ & $P$ value \\
\hline \multirow{4}{*}{$\begin{array}{l}\text { Height Level of crown In Rela- } \\
\text { tion to Occlusal Plane }\end{array}$} & Level 1 & 0 & 0 & 0 & 0 & ------ \\
\hline & Level 2 & 68.1 & 56.5 & 56.5 & 50 & 0.13 ns \\
\hline & Level 3 & 29.01 & 30.4 & 30.4 & 38.8 & $0.42 \mathrm{~ns}$ \\
\hline & Level 4 & 2.7 & 13.04 & 13.04 & 11.2 & $0.002^{*}$ \\
\hline \multirow{2}{*}{$\begin{array}{l}\text { Transvers nearest of crown in } \\
\text { The Relation to Midline }\end{array}$} & Distant & 27.2 & 39.1 & 39.1 & 38.8 & $0.057 \mathrm{~ns}$ \\
\hline & Close & 72.7 & 60.8 & 60.8 & 61.1 & $0.059 \mathrm{~ns}$ \\
\hline \multirow{2}{*}{ Canine Position } & Lingual or palatal & 52.7 & 17.3 & 17.3 & 16.6 & $0.003^{*}$ \\
\hline & Buccal & 47.2 & 82.6 & 82.6 & 83.3 & $0.005^{*}$ \\
\hline \multirow{3}{*}{ Canine Angulation to Medline } & $0-15$ & 41.8 & 60.8 & 60.8 & 66.6 & $0.004^{*}$ \\
\hline & $15-30$ & 36.3 & 17.3 & 17.3 & 22.4 & $0.07 \mathrm{~ns}$ \\
\hline & $>30$ & 21.8 & 17.3 & 17.3 & 11.2 & $0.31 \mathrm{~ns}$ \\
\hline \multirow{3}{*}{$\begin{array}{l}\text { Position of The Canine Apex } \\
\text { Related to the Adjacent Teeth }\end{array}$} & Canine zone & 29.01 & 69.5 & 69.5 & 50 & $0.007^{*}$ \\
\hline & $1^{\text {st }}$ premolar zone & 53.6 & 21.7 & 21.7 & 38.8 & $0.01^{*}$ \\
\hline & $2^{\text {nd }}$ premolar zone & 16.3 & 8.6 & 8.6 & 11.2 & $0.36 \mathrm{~ns}$ \\
\hline \multirow{4}{*}{$\begin{array}{l}\text { Mesiodistal Position of Canine } \\
\text { Tip to Adjacent Tooth }\end{array}$} & Distal & 32.7 & 73.9 & 73.9 & 72.2 & $0.005^{*}$ \\
\hline & Distal to long axis & 24.5 & 4.3 & 4.3 & 11.2 & $0.04^{*}$ \\
\hline & Mesial to long axis & 15.4 & 8.6 & 8.6 & 5.6 & $0.24 \mathrm{~ns}$ \\
\hline & Mesial & 27.2 & 13.04 & 13.04 & 11.2 & $0.13 \mathrm{~ns}$ \\
\hline
\end{tabular}

Table 1: Comparison between all quadrants regarding all parameters.

$\mathrm{N}$; count; \%: percentage; *significant difference. 
Comparison between different levels of maxilla and mandible among right and left sides

The comparison was performed between different levels using the Chi-square test, which revealed a significant difference in counts with different superscript letters as $\mathrm{P}<0.05$, while the insignificant revealed difference in counts with the same superscript letters as $\mathrm{P}>0.05$ as presented in table 2 and figure 5 .

Maxillary right side: level 2 is significantly higher than all other levels, then level 3 also was significantly higher than level 1 and 4 , while there was an insignificant difference between level 1 and 4 .

Maxillary left side: level 2 was significantly higher than all other levels, followed by level 3 was also significantly higher than level 1 and 4; level 4 was significantly higher than level 1.

Mandibular right and left sides: level 2 was insignificantly higher than level 3, while both levels 2 and 3 were significantly higher than levels 4 and 1 . Also, there was an insignificant difference between levels 1 and 4 .

\section{Discussion}

\begin{tabular}{|c|c|c|c|c|c|c|c|c|c|c|}
\hline \multirow[b]{2}{*}{ rch } & \multirow{2}{*}{$\begin{array}{c}\text { Side/ } \\
\text { Total N }\end{array}$} & \multicolumn{2}{|c|}{ Level 1} & \multicolumn{2}{|c|}{ Level 2} & \multicolumn{2}{|c|}{ Level 3} & \multicolumn{2}{|c|}{ Level 4} & \multirow[b]{2}{*}{$\begin{array}{c}\mathrm{P}- \\
\text { value }\end{array}$} \\
\hline & & $\mathbf{N}$ & $\mathbf{0}$ & $\mathbf{N}$ & $\%$ & $\mathbf{N}$ & $\%$ & $\mathbf{N}$ & $\%$ & \\
\hline \multirow{2}{*}{$a x$} & & $0^{\mathrm{a}}$ & 0 & $75^{b}$ & .1 & $32^{c}$ & 01 & $3^{\mathrm{a}}$ & 2.7 & \\
\hline & & 0 & 0 & 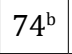 & 4 & $5^{c}$ & .9 & & 3.5 & 0.001 \\
\hline \multirow{2}{*}{ Iandible } & & $0^{\mathrm{a}}$ & 0 & $13^{b}$ & 5 & $7^{\mathrm{b}}$ & 30.4 & $3^{\mathrm{a}}$ & 13.04 & 001 \\
\hline & Lt (18) & $0^{\mathrm{a}}$ & 0 & $9^{\mathrm{b}}$ & 50 & $\mathrm{~b}$ & 38.8 & $2^{\mathrm{a}}$ & 11.2 & $0.001^{*}$ \\
\hline
\end{tabular}

Table 2: Comparison between different levels of maxilla and mandible among right and left sides.

$\mathrm{N}$; count; \%: percentage; *significant difference.

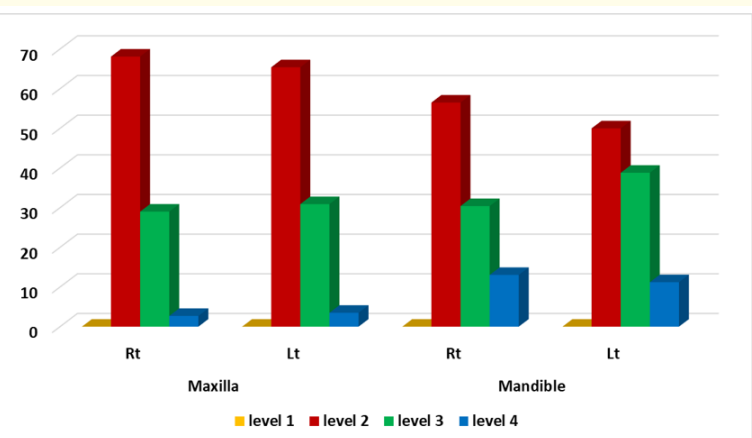

Figure 5: Comparison between different levels of maxilla and mandible among right and left sides.
Knowing the prevalence of impacted teeth is essential for practitioners for early recognition and interceptive treatment. Dental impaction is usually found in teenagers and adults at the third molar and upper canines areas. The cuspid features a complicated eruption pattern and is one of the last teeth to erupt in the dental arch. this tooth might not have an eruption process in an exceedingly natural way. Functional and esthetic aspects associated with the canine are of great importance; however, it frequently impacts. The most significant number of impacted teeth occurs with the lower third molar, followed by the upper third molar. Dental impaction occurs mainly in those teeth that erupt late as the upper canine and lower second premolar teeth. It occurs in a 3:1 ratio for the female gender and a higher frequency on the dental arch's left side. Canine impaction is more frequent within the maxilla and tends towards being unilateral [8-13,25].

Maxillary canines support the bottom of the alar and upper lip necessary for smiles and esthetics [31]. Furthermore, it provides canine guidance for mandibular movements. A disorder has been defined as a tooth that's thwarted from ultimately erupting into a natural functional position within the expected timeframe, usually related to an absence of space, physical obstruction by another tooth, or a deviant eruption path [6].

Some studies had reported the maxillary canines as the most often impacted teeth [16]; others had recorded it second after the third molars [21]. This high rate of impaction of upper canines was attributed to the fact that they are the last teeth to develop and travel long and tortuous paths before coming into functional occlusion. Through this long journey, they are frequently vulnerable to displacements and mechanical obstructions from adjacent teeth and also the process of pneumatization within the maxilla [3].

This study could help the dentist learn more about the prevalence of impacted canines and promotes a good understanding of the early diagnosis. If done correctly and timely, interdisciplinary treatment protected the patient from esthetic and functional discrepancies and prevented many unwanted complications by implementing preventive measures $[6,23]$.

Furthermore, in the present study, the age range was set between 16 and 40 years because the root completion occurred three years after the complete eruption of the upper canine, and after 40 years, periodontal and periapical pathologies might affect the presence of permanent teeth. This study had limitations in the small sample size, and the sample population was the only representative of the patient at a university orthodontic clinic; thus, wider population groups should be studied in Egypt in further research. 
Prevalence of Impacted Canine Among Adult Orthodontic Patients: A Retrospective Study

Screening of 3560 panoramic radiographs was performed in the current research collected from different orthodontic clinics related to Cairo, Azhar, Ain Shams and Alexandria universities.

The criteria required was fulfilled on 188 panoramic radiographs.

In this study, all the parameters written in the patient sheet to collect the information from the recorded file of the patient were based on a previous study [18].

The difficulty level was not significant between the four-quadrant of the studied sample. The most significant level of canine impaction in all four quadrants of the studied sample was level 2; this reveals that most of the impactions were at a level that is attainable for orthodontic extrusion.

Many studies assessed the prevalence of impacted teeth among different study populations [14]. The present study assessed the prevalence of impacted canines without considering the impaction of other teeth $[2,19,33]$. Maxillary canines impactions (84.4\%) were reported as more common than mandibular impactions $(15.5 \%)[16,24,28]$.

The present study resulted in $4.46 \%$ of maxillary canine impaction incidence in the Egyptian population, which disagrees with a study done in Greece that found that the North Greek population had a maxillary canine impaction incidence of $8.4 \%$ [14].

A study on the Panoramic x-rays of an Iraqi population involving 1050 cases revealed that the maxillary canine impaction prevalence was $6.28 \%$ [28]. Twenty-six thousand thirty-nine southern Chinese children and adolescents were investigated for impacted maxillary canines 533 (2.1\%) presented with at least one impacted maxillary canine [6]. Another study investigated the impaction of maxillary canines in 4133 patients in west India and reported a prevalence of $2.78 \%$ to have at least one impacted maxillary canine. Reported 36 cases out of 1368 cases to have at least one impacted maxillary canine with a prevalence rate of $2.14 \%$ [17]. Investigated 580 panoramic radiographs of Bangladeshi patients and found that impacted maxillary canines were present in only $7(1.2 \%)$ radiographs [26,27] a prevalence of $1.36 \%$ was reported by [24], who conducted a retrospective investigation on 3800 panoramic x-rays. The result revealed that the incidence of maxillary canine impaction was $(1.62 \%)$.
The incidence of canine impaction varies with the population studied. The different results may be attributed to the racial differences and differences in the methodology of the study. The prevalence of impacted canines among females was $3.4 \%$ and $1.85 \%$ among males. A significant association between gender and canine impaction $(\mathrm{P}<0.05)$ was found in the current study, indicating that females had a higher prevalence of canine impaction than males, which is in agreement with other studies [4,15,19,28-33]. These results are consistent with those obtained by other studies reporting that the majority of maxillary impactions occur unilaterally $[3,14,26,27,33]$. No significant $(P>0.05)$ difference in the prevalence of right or left canine impaction. These findings agreed with studies done in Turkey, Greece [14,16].

Other studies reported left side impactions to be more common than right side impactions $[17,19,26,27,34]$ disagree with this study's result.

Panoramic radiographs were used by the investigators who performed previous studies on the prevalence of impacted teeth. Panoramic $x$-rays only give a general overview but do not give the precise localization of an impacted canine in three-dimensional space. However, panoramic radiography is the most available method in Egyptian universities.

This study revealed an insignificant correlation between pegshaped lateral incisor teeth and upper impacted canine teeth. Correlation between impacted canine and missed the second premolar, A significant, weak positive correlation between mandibular left impacted canine and mandibular right and left missed the second premolar. Regarding the correlation between impacted canine and missed wisdom, there was a significant $(\mathrm{P}<0.005)$, weak $(<0.5)$ negative (-) correlation between maxillary right impacted canine and mandibular right missed wisdom. Also, there was a significant $(\mathrm{P}<0.05)$, weak $(<0.5)$, positive $(+)$ correlation between mandibular left impacted canine and mandibular left missed wisdom.

In this study, the percentage of impacted canine teeth derived from the orthodontic clinic of a major university in Egypt was (5.28\%), and this percent was divided into (84.4\%) maxillary impacted canine teeth and (15.6\%) mandibular impacted canine teeth, which agreed with other studies done for Saudi patients and reported that $(3.6 \%)$ of patients had at least one impacted canine [1]. A research performed in 406 digital panoramic x-rays and found that impacted canines were (4.19\%) in south India [33]. 
On A Palestine population,2200 patients were examined and recorded $82(3.7 \%)$ cases of at least one impacted maxillary canine [4].

\section{Conclusions}

The Prevalence of impacted canine teeth among a sample of orthodontic patient orthodontic clinics in the Egyptian population in this study is $5.28 \%$.

The level of difficulty of canine impaction was insignificant between the four quadrants, and it was mostly in level 2.

\section{Recommendations}

Larger scale studies are recommended for better evaluation and description of the detection of impacted canine teeth in orthodontic clinics.

- Prevalence in a larger sample of the Egyptian population has impacted canine teeth.

- Further study the etiology of increasing impacted canine teeth in the Egyptian population.

- Interpretation of the prognosis of impacted canine either palatally or labially.

\section{Bibliography}

1. AA Zahrani. "Impacted cuspids in a Saudi population: prevalence, etiology, and complications". Egyptian Dental Journal 39.1 (1993): 367-374.

2. Alif SM., et al. "Panoramic Radiological Study to Identify Locally Displaced Maxillary Canines in Bangladeshi Population". Imaging Science in Dentistry 41 (2011): 155-159.

3. Becker A and Chaushu S. "Etiology of maxillary canine impaction: a review". American Journal of Orthodontics and Dentofacial Orthopedics 148 (2015): 557-567.

4. Camilleri S. "The Prevalence of Impacted Permanent Maxillary Canines in Maltese School Children: A Pilot Study". Malta Medical Journal 1 (1995): 42-46.

5. Carlson H. "Studies on the rate and amount of eruption of certain human teeth". American Journal of Orthodontics and Oral Surgery 42 (1994): 78-91.
6. Chu FC., et al. "Prevalence of impacted teeth and associated pathologies-a radiographic study of the Hong Kong Chinese population". Hong Kong Medical Journal 9.3 (2003): 158-163.

7. Clark CA. "A method of ascertaining the relative position of unerupted teeth by means of film radiographs". Proceedings of the Royal Society of Medicine 3 (1910): 87-90.

8. Dewel BF. "Clinical observations on the axial inclination of teeth". American Journal of Orthodontics 35.2 (1949): 98-115.

9. Dewel BF. "The upper cuspid: Its development and impaction". The Angle Orthodontist 19 (1949): 79-90.

10. Ericson S and Kurol J. "Longitudinal study and analysis of clinical supervision of maxillary canine eruption". Community Dental and Oral Epidemiology 14 (1986): 112-116.

11. Ericson S and Kurol J. "Radiographic examination of ectopically erupting maxillary canines". American Journal of Orthodontics and Dentofacial Orthopedics 91 (1987): 483-492.

12. Ericson S and Kurol J. "Radiographic assessment of maxillary canine eruption in children with clinical signs of eruption disturbance". European Journal of Orthodontics Oxford 8.3 (1986): 133-140.

13. Ewan GE and Sheridan W. "Locating impacted cuspids: using the shift technique". American Journal of Orthodontics St. Louis 41.12 (1956): 926-929.

14. Fardi A., et al. "Incidence of Impacted and Supernumerary Teeth-A Radiographic Study in a North Greek Population". Medicine Oral, Patología Oral y Cirugía Bucal 16 (2011): e56e61.

15. Gashi A., et al. "The Incidence of Impacted Maxillary Canines in a Kosovar Population". International Scholarly Research Notices (2014).

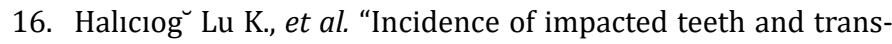
migrated canines-A radiographic study in Turkish dental patients". Clinical Research Dental 36 (2012): 42-50.

17. Hijawi SI., et al. "Prevalence of Impacted and Transmigrated Canine among Palestinian People-Jenin District". Journal of Basic and Applied Research International 2 (2016): 272-276. 
18. Hamad Journal of Clinical and Experimental Dentistry 10.4 (2018): e327-334

19. Kifayatullah J., et al. "Prevalence and Patterns of Impacted Maxillary Canine". Pakistan Oral and Dental Journal 35.1 (2015): 57-61.

20. Lindauer SJ. "Canine impaction was identified early with panoramic radiographs". Journal of the American Dental Association 123 (1992): 91-97.

21. Litsas G and Acar A. "A review of early displaced maxillary canines: etiology, diagnosis and interceptive treatment". The Open Dentistry Journal 5 (2011): 39-47.

22. Massler MS I. "Studies in tooth development theories of the eruption". American Journal of Orthodontics and Oral Surgery 27 (1941): 552-576.

23. Mirabella D., et al. "Substitution of Impacted Canines by Maxillary First Premolars: A Valid Alternative to Traditional Orthodontic Treatment". American Journal of Orthodontics and Dentofacial Orthopedics 143 (2013): 125-133.

24. Mustafa A. "Prevalence of Impacted Canine Teeth in the College of Dentistry, King Khalid University-A Retrospective Study". International Journal of Health Sciences and Research 4 (2014): 211-214.

25. Nogueira AS., et al. "Principais transtornos ocasionados por dentes inclusos [Clinical and radiographic aspects related to the main perturbations caused by unerupted teeth]". Revista da Associação Paulista de Cirurgiões Dentistas 51 (1997): 247249.

26. Patil SR., et al. "CBCT Evaluation of the Prevalence of Impacted Maxillary Canines in a Saudi Arabian Population: A Preliminary Study". International Journal of Human and Health Sciences 2 (2018): 31-34.

27. Patil S., et al. "Prevalence of Impacted Canines in Population of Western Part of India”. Universal Research Journal of Dentistry 4 (2014): 148.

28. Saeed 0., et al. "Prevalence of Canine Impaction in a Selected Sample of Sulaimani City Population". International Journal of Developmental Neuroscience 5 (2015): 5816-5819.
29. Sajnani AK and King NM. "Complications associated with the occurrence and treatment of impacted maxillary canines". Singapore Dental Journal 35 (2014): 53-57.

30. Sajnani AK and King NM. "Prevalence and characteristics of impacted maxillary canines in Southern Chinese children and adolescents". Journal of investigative and clinical dentistry 5 (2014): 38-44.

31. Sajnani AK. "Permanent maxillary canines-review of eruption pattern and local etiological factors leading to impaction". Journal of investigative and clinical dentistry 6 (2015): 1-7.

32. Sajnani AK and King NM. "Prevalence and Characteristics of Impacted Maxillary Canines in Southern Chinese Children and Adolescents". Journal of Investigative and Clinical Dentistry 5 (2014): 38-44.

33. Sharmila R. "Incidence of Impacted Canine Using Orthopantomogram". Pharmaceutical Sciences and Research 8 (2016): 921-922.

34. Watted N., et al. "Incidence of Canine Impaction in Palestinian Population". Journal of Advanced Oral Research 5 (2014): 4-10.

35. Weinmann JP. "Bone changes related to the eruption of the teeth". The Angle Orthodontist 11.2 (1944): 83-99.

\section{Assets from publication with us}

- Prompt Acknowledgement after receiving the article

- Thorough Double blinded peer review

- Rapid Publication

- Issue of Publication Certificate

- High visibility of your Published work

Website: www.actascientific.com/

Submit Article: www.actascientific.com/submission.php Email us: editor@actascientific.com

Contact us: +919182824667 